\title{
The Effect of Intra-amniotic Injection of Triiodothyronine on Pulmonary Maturity in Lambs at 130 Days Gestation
}

\author{
ANDREW R. KORDA, SUSAN F. FLEMING, CECILIA SENIOR, CORAL G. DUCK-CHONG, \\ DAVID J. HENDERSON-SMART, GAVIN RAMSEY, DONALD A. SHUTT, PETER RUSSELL, AND \\ RODNEY P. SHEARMAN \\ Departments of Obstetrics and Gynaecology and Histology and Embryology, Perinatal Medicine and Anatomical \\ Pathology, University of Sydney and King George V Hospital, Sydney, Australia
}

\begin{abstract}
Summary
Saline or triiodothyronine $\left(\mathrm{T}_{3}\right)(50-1000 \mu \mathrm{g})$ was injected into the amniotic sac of 17 pregnant ewes under general anesthesia at 130 days gestation. Forty-eight $h$ later, the lambs were delivered by hysterotomy. Cord plasma $T_{3}$ and cortisol and amniotic fluid $T_{3}$ were assayed, and the maturity of the fetal lung was assessed in terms of its pressure-volume response and its surfactant (lamellar body phospholipid) content. With the highest dose of $T_{3}$, cord plasma $T_{3}$ and cortisol were raised, and lung maturity was enhanced compared with saline-treated controls; the pressure-volume curve showed increased hysteresis on inflation and deflation, and the lung retained air on return to zero pressure. There was also an apparent, but not statistically significant, increase in the lamellar body phospholipid content of the lung. Irrespective of treatment, lungs which were more mature, in terms of their pressure-volume characteristics, tended to contain a higher proportion of lamellar body phospholipid relative to total phospholipid.
\end{abstract}

\section{Abbreviations}

$T_{4}$, thyroxine

$T_{3}$, triiodothyronine

Pregnant women threatening premature delivery are often treated with glucocorticoid in an attempt to accelerate maturation of the fetal lungs and thus avoid hyaline membrane disease in the neonate (17). However, the treatment is not always effective and early results suggested that such treatment may increase the risk of fetal death in pregnancies complicated by severe hypertension-edema-proteinuria syndromes (17). Hence, other substances which may accelerate the process of lung maturation need to be considered.

The results of several investigations in the lamb, rat, and rabbit strongly suggest that thyroid hormones promote lung maturation and surfactant production $(4,9-11,22,23,25,27)$. In addition, it has been shown that $\mathrm{T}_{4}(24)$ and $\mathrm{T}_{3}$ levels $(6)$ in cord blood are lower in infants who develop hyaline membrane disease than in those who do not, although there is disagreement (16). One recent uncontrolled study in the human has reported possible beneficial effects of intra-amniotic thyroxine on fetal pulmonary maturity (18), but the number of cases studied was small.

The present investigation was designed to study the effect of intra-amniotically administered thyroid hormone on fetal lung maturation in the sheep using $T_{3}$ rather than $T_{4}, T_{3}$ being the more active form of thyroid hormone. The hormone was admin-

Received August 27, 1981; accepted February 7, 1984.

Reprint requests may be addressed to A. R. Korda, M.D., Department of Obstetrics and Gynaecology, University of Sydney, Sydney, NSW 2006, Australia. istered intra-amniotically rather than maternally, because the sheep placenta is only very slightly permeable to $T_{3}(8)$ and it has been shown that thyroid hormone is readily transferred from the amniotic fluid to the fetal circulation (26).

\section{MATERIALS AND METHODS}

Treatment of ewes and lambs. Seventeen sheep (13 pure bred Merino ewes and four Dorset Horn/Merino cross-bred ewes) were used. Pregnancies were achieved by single matings after the induction of estrus, and confirmed by test matings. At 116 days gestation, the pregnant ewes were transported from open pasture to the university animal house for acclimatization, where they were maintained in individual pens and fed lucerne chaff. The experiments were conducted in a blind fashion where $\mathrm{T}_{3}(20 \mu \mathrm{g} /$ $\mathrm{ml}$ saline) and saline controls were packaged identically. The code was broken at the end of experimentation on a group of animals so that an ongoing analysis of the results was possible, and modification of the protocol could be carried out until an appropriate dose of $\mathrm{T}_{3}$ was achieved. At 130 days gestation, under general anesthesia (after $12 \mathrm{~h}$ fasting), a lower paramedian incision was made in the abdomen, and the uterus was exposed. The fetal neck was grasped and $20 \mathrm{ml}$ of amniotic fluid was withdrawn. $T_{3}(50-1000 \mu \mathrm{g})$ or saline was injected by the same needle, so that it was introduced as close as possible to the fetal mouth. The incision was closed, and the animals were returned to their cages with only local antibiotic cover to their incision.

After $48 \mathrm{~h}$, the lambs were delivered by hysterotomy under general anesthesia. Prior to delivery of the lamb, $20 \mathrm{ml}$ of amniotic fluid and $10 \mathrm{ml}$ of cord venous blood were taken. The blood was collected into heparinized tubes and after centrifugation, the plasma was stored at $-20^{\circ} \mathrm{C}$ until required for analysis.

In order to prevent gasping, the lambs were sacrificed by intravenous pentobarbitone at the moment of cord clamping and before delivery of the fetal head. The lambs so delivered were drained immeditely of tracheal fluid through an endotracheal tube. The left side of the chest wall was then removed, and two wedges of tissue were excised from the left lobe, one from the apical margin of the upper lobe (about $2.5 \mathrm{~g}$ ) and one from the basal margin of the lower lobe (about $4.5 \mathrm{~g}$ ). A thin section of lung, obtained by cutting transversely through the center of each wedge, was fixed for light microscopy. The remainder of each lung sample was rinsed in ice-cold $0.25 \mathrm{M}$ sucrose and used as soon as possible for the determination of lamellar body phospholipid and total lung phospholipid.

The left main bronchus was then carefully dissected and occluded with a suture and the right lung, which remained in situ, was used for pressure-volume studies.

Hormone assays. $\mathrm{T}_{3}$ in amniotic fluid or cord venous plasma, and cortisol in cord venous plasma were assayed by double 
antibody radioimmunoassay using reagents prepared by Diagnostic Products Corp., Los Angeles, CA.

Light microscopy. Tissue was fixed in $10 \%$ formalin in cacodylate buffer and processed according to standard procedures used for human autopsy specimens. Criteria used to judge maturity included development of the terminal air sac, flattening of the alveolar cells, thinning of the blood-air barrier, and the absence of mesenchymal tisues among the pneumatocytes.

Lung and lamellar body phospholipid determinations. The lamellar body fraction was isolated by isopycnic density gradient centrifugation, as described previously (7), with the following modifications. Five per cent (w/v) lung homogenates were prepared in 1.2 M sucrose, using 1.25-g portions of chopped lung, and the homogenate $(5 \mathrm{ml})$ was overlaid with a discontinuous gradient, consisting of $2 \mathrm{ml} 0.85 \mathrm{M}$ sucrose, $2 \mathrm{ml} 0.75$ sucrose, and $2.5 \mathrm{ml} 0.25 \mathrm{M}$ sucrose, prior to centrifugation at $125 \times g$ and $80,000 \times g$. The band of material which came to equilibrium at the $0.25 \mathrm{M} / 0.75 \mathrm{M}$ sucrose interface was collected as the lamellar body fraction. Electron microscopy (7) confirmed that this fraction consisted mainly of lamellar bodies or membranous structures apparently of lamellar body origin, whereas fragments of plasma membrane predominated in the small band of material which floated at the $0.75 \mathrm{M} / 0.85 \mathrm{M}$ sucrose interface (DuckChong C. G., and B. Duncan, unpublished data). The phospholipid content of the lamellar body fraction and the whole homogenate (diluted 1:5 with $0.9 \% \mathrm{NaCl}$ ) was determined as described previously (7).

Pressure-volume measurements. The trachea was attached to a pressure-volume apparatus as described by Avery and Mead (3). The lungs were twice slowly inflated and deflated with air to $30 \mathrm{~cm} \mathrm{H}_{2} \mathrm{O}$ pressure; then pressure-volume readings were commenced. Readings were taken at $5-\mathrm{cm}$ pressure intervals or less allowing $2 \mathrm{~min}$ of equilibration at each pressure. The area of the pressure-volume curve was then expressed in arbitrary planimeter units.

\section{RESULTS}

At the time of delivery of the lambs, that is, $48 \mathrm{~h}$ after treatment, $T_{3}$ was present in the amniotic fluid of all $T_{3}$-treated animals, but not detectable in the amniotic fluid of saline-treated controls. In those who received 100-1000 $\mu \mathrm{g} \mathrm{T}_{3}$, significant increases in cord venous plasma $T_{3}$ concentrations were noted (Table 1). At the highest dose of $\mathrm{T}_{3}$, but not at lower doses, there was also a significant increase in the concentration of cortisol in the plasma, due mainly to the fact that one of the $T_{3}$-treated fetuses had a serum cortisol of $160 \mathrm{nmol} /$ liter. There was also an increase in the maturity of the fetal lungs, as indicated by a 6-fold increase in the area of the pressure-volume curve (Table

Table 1. Effect of intra-amniotic administration of $T_{3}$ on cord venous $T_{3}$ and cortisol levels and on lung pressure-volume curves in lambs delivered $48 \mathrm{~h}$ after treatment*

Cord venous plasma

\begin{tabular}{clllll} 
& \multicolumn{1}{c}{$\begin{array}{c}\text { Dose of } \\
\mathrm{T}_{3}(\mu \mathrm{g})\end{array}$} & \multicolumn{1}{c}{$\begin{array}{c}\mathrm{T}_{3} \\
(\mathrm{nmol} / \text { liter })\end{array}$} & \multicolumn{2}{c}{$\begin{array}{c}\text { Cortisol } \\
\text { (nmol/liter) }\end{array}$} & \multicolumn{2}{c}{ (planimeter U) } \\
\hline 0 & $0.40 \pm 0.03$ & $44 \pm 4$ & $(7) \dagger$ & $29 \pm 10$ & $(6) \dagger$ \\
$0 \ddagger$ & 1.34 & 40 & $(1)$ & 162 & $(1)$ \\
50 & $0.42(0.35,0.49)$ & $59(53,65)$ & $(2)$ & $39(38,40)$ & $(2)$ \\
$100-200$ & $0.82 \pm 0.06^{* * *}$ & $63 \pm 17$ & $(3)$ & $27(22,31)$ & $(2)$ \\
1000 & $2.00 \pm 0.58^{* *}$ & $89 \pm 25^{*}$ & $(4)$ & $182 \pm 72^{*}$ & $(4)$ \\
\hline
\end{tabular}

* Values represent individual data or the mean \pm SEM. The asterisks indicate the significance of the difference between that value and the corresponding value for the control group: ${ }^{*} p<0.05,{ }^{* *} p<0.01,{ }^{* * *} p$ $<0.001$; Student's $t$ test.

$\dagger$ The number of animals is indicated in these parentheses.

$\ddagger$ Atypical individual; data excluded from statistical analysis.
1). One atypical individual in the control group had a high cord plasma $\mathrm{T}_{3}$ level and unusually mature lungs, but a plasma cortisol level comparable with that of the other animals in the control group. This fetus was also comparable in size to the others in the control group.

Figure 1 illustrates the difference in the pressure-volume response characteristics of "immature" and "mature" lungs. To allow the shapes of the different curves to be compared directly, the data were normalized by expressing volumes as a percentage of total lung volume for each lung. More mature lungs show marked hysteresis and retention of air on return to zero pressure. Only one of seven animals in the control group showed a mature response, compared with three of four in the group treated with $1000 \mu \mathrm{g} \mathrm{T}_{3}$ (Fig. 1). The difference between these two proportions is significant $(p=0.04)$.

Analysis of lung phospholipids showed an apparent increase in lamellar body phospholipid in response to $\mathrm{T}_{3}$ treatment (Table 2 ), but there was considerable variation between individuals and the differences were not statistically significant. Since data expressed per $\mathrm{g}$ lung may be influenced by changes in tissue composition, for example, changes in its water or glycogen content, the lamellar body phospholipid content of the lung was also expressed as a percentage of its total phospholipid content. Lamellar body phospholipid levels, whether expressed in terms of tissue wet weight or relative to total lung phospholipid, were significantly higher in the upper lobe than in the lower lobe in controls and those treated with lower doses of $\mathrm{T}_{3}$, but the difference between lobes was not significant in those treated with $1000 \mu \mathrm{g} \mathrm{T}_{3}$ (Table 2).

When data for lung phospholipids were related to the area of the pressure-volume curve for individual lambs, a direct correlation between the percentage lamellar body phospholipid content of the lung and "maturity" of the pressure-volume response was apparent, irrespective of treatment (Fig. 2). All four lungs with pressure-volume areas greater than $100 \mathrm{U}$ contained more than $8 \%$ lamellar body phospholipid, whereas of the nine lungs with pressure-volume areas less than 100 , all but one contained less than $8 \%$ lamellar body phospholipid. The difference between these two proportions is highly significant $(p<0.001)$. This relationship was independent of the sex of the fetuses.

All lungs studied by light microscopy showed histological maturity.

\section{DISCUSSION}

These data show that fetal lung maturity can be enhanced by the intra-amniotic administration of $\mathrm{T}_{3}$ in the sheep, and thus lend support to other studies in which the effect of thyroid hormones on lung maturation has been investigated $(4,22,25$, 27).

The finding of histological maturity in all lambs at 132 days gestation irrespective of treatment is in agreement with Kikkawa et al. (15), who could find no difference by light microscopy between lambs of 121 days gestation and term. The finding also indicates that histological maturity (as defined in "Materials and Methods") is not synonymous with functional maturity and that the enhanced lung compliance observed in some $\mathrm{T}_{3}$-treated fetuses did not result from gross changes in lung morphology.

Using electron microscopy, it has been shown that beyond 120 days gestation in the lamb there is a marked increase in the number of lamellar bodies present in Type II cells of the alveolar epithelium $(1,5)$. These lamellar bodies are the source of surfactant, the phospholipid-rich substance which lowers surface tension within the lungs and prevents alveolar collapse on expiration. The ultracentrifugation technique used in this study allowed quantitation of the amount of lamellar body (or surfactant) phospholipid in the lung. There was an overall correlation between the lamellar body phospholipid content of the lung and the maturity of the lung with respect to its pressure-volume response (Fig. 2). However, while increased surfactant availability 

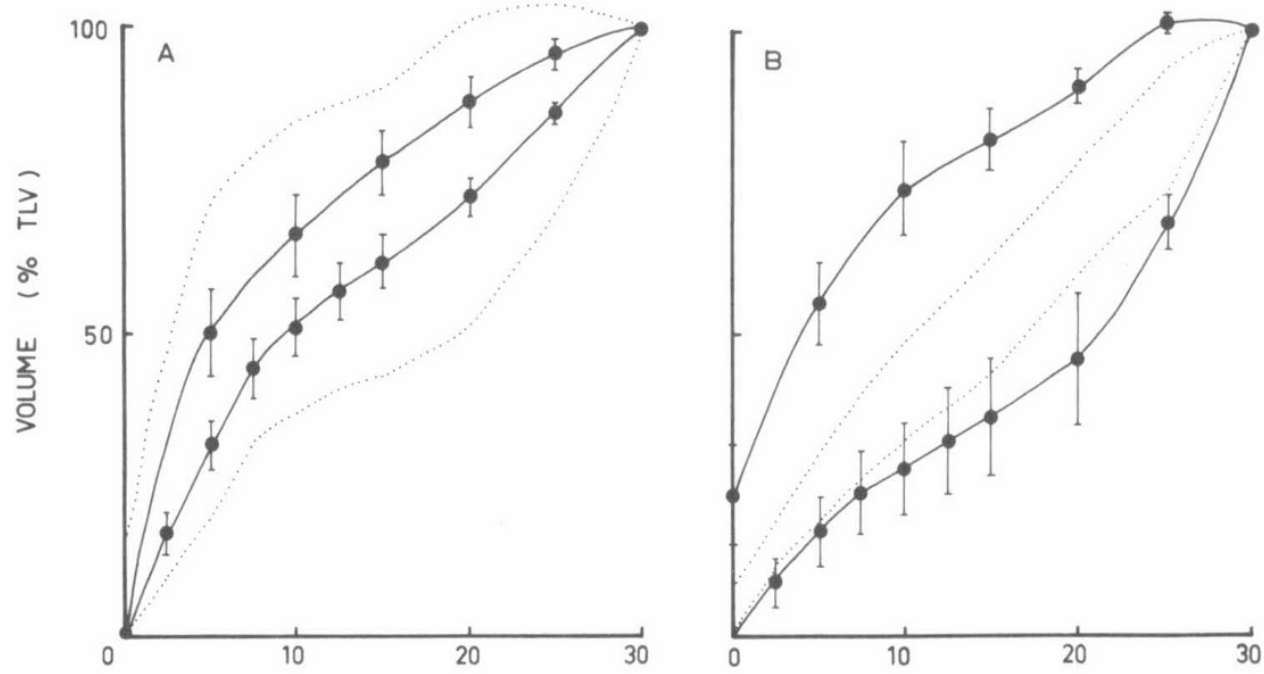

PRESSURE $\left(\mathrm{cm} \mathrm{H} \mathrm{H}_{2} \mathrm{O}\right)$

Fig. 1. Pressure-volume curves of lungs of fetal lambs $48 \mathrm{~h}$ after treatment with either saline $(A)$ or $1000 \mu \mathrm{g} \mathrm{T}_{3}(B)$. Volumes are expressed as a percentage of total lung volume ( $T L V$ ) at a pressure of $30 \mathrm{~cm} \mathrm{H}_{2} \mathrm{O}$. In $A$, the solid line represents the mean of data for the six lambs who showed a typical immature response (area $<100$ planimeter $\mathrm{U}$, no air retention on deflation). In $B$, the solid line indicates the mean for the three lambs who showed a typical mature response (area $>100$ planimeter $\mathrm{U}$, with air retention on deflation). The bars indicate \pm 1 SEM. Dotted lines indicate data for a single lamb in each group, whose lungs were unusually mature $(A)$ or immature $(B)$, compared with the others in the group.

Table 2. Effect of intra-amniotic administration of $T_{3}$ on lung phospholipids*

\begin{tabular}{|c|c|c|c|c|c|}
\hline \multirow{2}{*}{$\begin{array}{l}\text { Dose of } \\
T_{3}(\mu \mathrm{g})\end{array}$} & \multicolumn{2}{|c|}{$\begin{array}{l}\text { Lamellar body phos- } \\
\text { pholipid (mg/g lung) }\end{array}$} & \multicolumn{2}{|c|}{$\begin{array}{l}\text { Lamellar body phospho- } \\
\text { lipid } \dagger / \text { Total lung phos- } \\
\text { pholipid }\end{array}$} & \\
\hline & Upper lobe & Lower lobe & Upper lobe & Lower lobe & \\
\hline 0 & $\begin{array}{l}0.63 \\
\pm 0.10\end{array}$ & $\begin{array}{l}0.48 \\
\pm 0.09 \ddagger\end{array}$ & $\begin{array}{c}6.9 \\
\pm 1.0\end{array}$ & $5.3 \pm 0.9 \ddagger$ & $(6)^{*}$ \\
\hline $0^{*}$ & 1.61 & 1.30 & 15.8 & 11.1 & (1) \\
\hline $50-200$ & $\begin{array}{l}0.86 \\
\pm 0.19\end{array}$ & $\begin{array}{l}0.58 \\
\pm 0.13\end{array}$ & $\begin{array}{c}8.6 \\
\pm 1.6\end{array}$ & $5.7 \pm 0.9 \ddagger$ & (4) \\
\hline 1000 & $\begin{array}{l}0.97 \\
\pm 0.29\end{array}$ & $\begin{array}{l}0.81 \\
\pm 0.21\end{array}$ & $\begin{array}{l}11.1 \\
\pm 3.4\end{array}$ & $9.0 \pm 2.2$ & (4) \\
\hline
\end{tabular}

* See footnotes to Table 1 .

$\dagger$ Lamellar body phospholipid (mg/g lung) expressed as a percentage of total lung phospholipid ( $\mathrm{mg} / \mathrm{g}$ lung).

$\ddagger$ The difference between this value and the corresponding value for the upper lobe is significant ( $p<0.05$, paired $t$ test).

possibly contributes to the more mature lung function observed in some of these fetuses, other factors such as tissue elasticity or the degree of alveolation $(1,20)$ may also be important.

There was a tendency for the upper lobe of the lung to be more mature than the lower lobe, especially in fetuses whose lungs had not been matured by $T_{3}$ treatment (Table 2). This finding is in agreement with the results of others $(5,12)$, who measured surface tension, pressure-volume characteristics, or the amount of total lung phospholipid, or disaturated phosphatidylcholine per mg DNA. They found a similar marked difference in the degree of maturity of the upper and lower lobes in lambs of 120-130 days gestation, which tended to disappear as the lungs matured.

In lambs given a single dose of $1000 \mu \mathrm{g} \mathrm{T}_{3}$, the cord plasma $\mathrm{T}_{3}$ level at the time of delivery approached that noted in lambs at term (21). However, as the half-life of $T_{3}$ in fetal lamb serum is known to be only about 4-6 h (8), the concentration of $T_{3}$ in the circulation must have been considerably higher earlier in the 48-h treatment period. Similarly, cortisol levels higher than those reported may have resulted from treatment with $1000 \mu \mathrm{g} \mathrm{T}$. This raises the possibility that the enhanced lung maturity, which was observed only in response to a very high dose of $T_{3}$, may have been mediated by a rise in cortisol. If this were so, then no advantage would be gained by using thyroid hormone instead of corticosteroid to enhance fetal lung maturity. However, it is likely that both hormones exerted an effect in such cases, since maturation of the lung is under multihormonal control $(11,19)$,

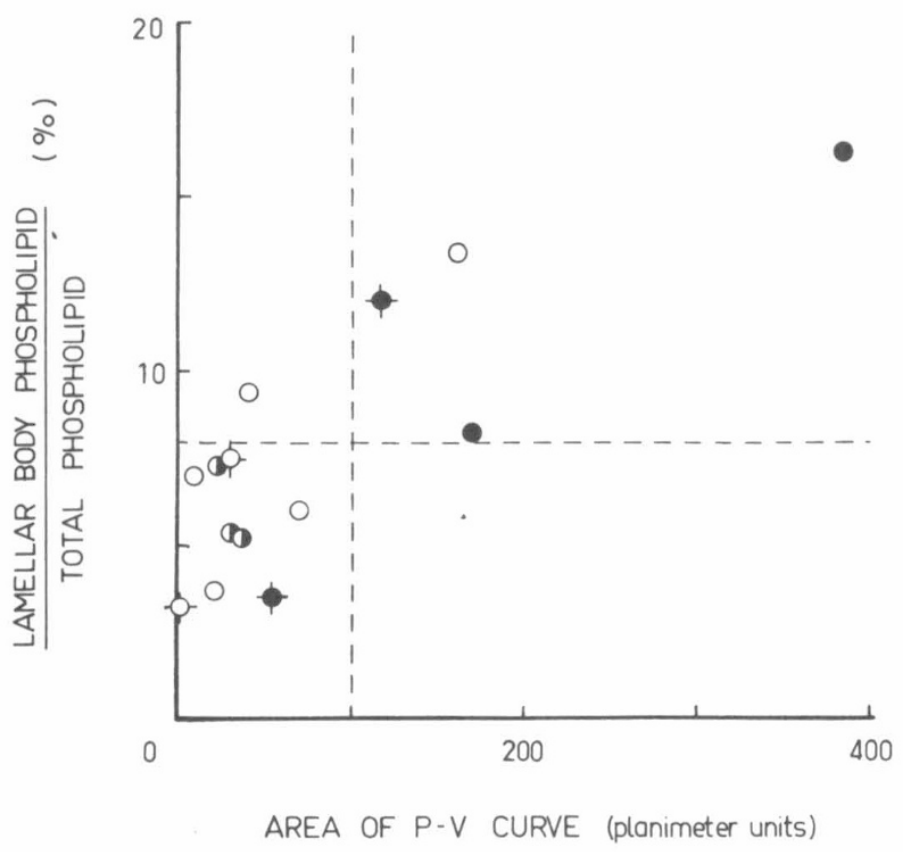

Fig. 2. The relationship between lung lamellar body phospholipid, expressed as a percentage of total lung phospholipid, and the area of the pressure-volume $(P-V)$ curve for individual lambs treated with saline $(O)$, 50-200 $\mu \mathrm{g} \mathrm{T}_{3}(\boldsymbol{\odot})$, or $1000 \mu \mathrm{g} \mathrm{T}_{3}(\bullet)$. The phospholipid data represent the mean of the values obtained for the upper and lower lobe of the lung. The data points derived from Dorset Horn/Merino Cross bred lambs are marked with a cross. 
and thyroid hormones and glucocorticoid seem to act in different ways $(4,10)$.

The use of agents such as thyroid hormones must always be approached with caution, because they affect many tissues. A beneficial effect on the lung may be offset by harmful effects on some other system. For example, brain development is dependent on thyroid hormones. Administration of $\mathrm{T}_{4}$ in large doses to neonatal rats resulted in structural and functional changes in the brain (13). The effects appeared to be due to premature switching to a more mature nerve cell production. Those neurones which had not made synaptic connections at that time died, with a resultant overall reduction in brain cell number.

It has never been established that the apparent enhancement of lung maturity in response to thyroid hormones does, in fact, represent a beneficial effect on the fetus in terms of improved respiratory performance and survival following premature delivery. In one study involving rabbits (27), a significantly higher number of deaths occurred in utero in $\mathrm{T}_{4}$-treated fetuses compared with their littermate controls. However, the survival of the prematurely delivered fetuses was not assessed.

In another study in the rat, in which $\mathrm{T}_{3}$ or $\mathrm{T}_{4}$ was administered to the mother, the lungs of some fetuses (delivered 2 days prematurely and maintained for $60 \mathrm{~min}$ in a humidicrib) showed widespread atelectasis, although the lungs of their littermates examined at the time of delivery appeared to have matured in response to the treatment (14). In the sheep, treatment of three fetuses by intravenous infusions of $T_{3}$ or $T_{4}$ at the rate of 1-12 $\mathrm{mg} /$ day did not lead to enhanced survival on premature delivery (2), and two other lambs given higher doses died in utero. In another study, administration of $150 \mu \mathrm{g} \mathrm{T}_{3}$ intravenously to the lamb in utero at 119 days gestation resulted in immediate fetal death (22).

Clearly, further investigation is needed to establish whether the apparent enhancement of lung maturity, observed in this and other studies, results in improved respiratory performance and survival on premature delivery, or whether toxic side effects outweigh the potential benefits of the treatment.

Acknowledgments. The authors wish to thank the staff at the Endocrine Laboratory, Royal Prince Alfred Hospital, Sydney for carrying out the assays of $\mathrm{T}_{3}$ in amniotic fluid and $\mathrm{T}_{3}$ and cortisol in cord venous plasma.

\section{REFERENCES}

1. Alcorn DA, Adamson TM, Maloney JE, Robinson PM 1981 A morphologic and morphometric analysis of fetal lung development in the sheep. Anat Res 201:655

2. Alexander G 1976 Maturation of the fetal lamb. Proc Endocrinol Soc Aust 19:37

3. Avery EM, Mead J 1959 Surface properties in relation to atelectasis and hyaline membrane disease. Am J Dis Child 97:517
4. Ballard PL, Benson BJ, Brehier A, Carter JP, Kriz BM, Jorgensen EC 1980 Transplacental stimulation of lung development in the fetal rabbit by $3,5-$ dimethyl-3'-isopropyl-1-thyronine. J Clin Invest 65:1407

5. Brumley GW, Chernick V, Hodson WA, Normand C, Fenner A, Avery ME 1967 Correlation of mechanical stability, morphology, pulmonary surfactant, and phospholipid content in the developing lamb lung. J Clin Invest 46:863

6. Cuestas RA, Lindall A, Engel RR 1976 Low thyroid hormones and respiratorydistress syndrome of the newborn. N Engl J Med 295:297

7. Duck-Chong, CG 1978 The isolation of lamellar bodies and their membranous content from rat lung, lamb tracheal fluid and human amniotic fluid. Life Sci $22: 2025$

8. Dussault JH, Hobel CJ, Distefano III JJ, Erenberg A, Fisher DA 1972 Triiodothyronine in maternal and fetal sheep. Endocrinology 90:1301

9. Erenberg A, Rhodes ML, Weinstein MM, Kennedy RL 1979 The effect of fetal thyroidectomy on ovine fetal lung maturation. Pediatr Res 13:230

10. Gross I, Wilson CM, Ingelson LD, Brehier A, Rooney SA 1980 Fetal lung in organ culture. III. Comparison of dexamethasone, thyroxine and methylxanthines. J Appl Physiol Respir Environ Exercise Physiol 48:872

11. Hitchcock KR, 1979 Hormones and the lung. I. Thyroid hormones and glucocorticoids in lung development. Anat Rec 194:15

12. Howatt WF, Avery ME, Humphreys PW, Normand ICS, Reid L, Strang LB 1965 Factors affecting pulmonary surface properties in the fetal lamb. Clin Sci 29:239

13. Jacobson M 1978 Developmental Neurobiology. Plenum Press, New York, p 226

14. Jewlachow V 1976 A morphological investigation of lung development. B.Sc. honours thesis, University of Sydney

15. Kikkawa Y, Motoyama EK, Cook CD 1965 The ultrastructure of the lung of the lambs: the relationship of osmiophilic inclusions and alveolar lining layer to fetal maturation and experimentally produced respiratory distress. Am J Pathol 47:877

16. Klein AH 1981 Thyroid function studies in cord blood from premature infants with and without RDS. J Pediatr 98:818

17. Liggins GC, Howie RN 1972 A controlled trial of antepartum glucocorticoid treatment for the prevention of the respiratory distress syndrome in premature infants. Pediatrics 50:515

18. Maschiach S, Barkai G, Sack J, Stern E, Goldman B, Brish M, Serr DM 1978 Enhancement of fetal lung maturity by intra-amniotic administration of thyroid hormone. Am J Obstet Gynecol 130:289

19. Mendelson CR, Johnston JM, Macdonald PC, Snyder JM 1981 Multihormonal regulation of surfactant synthesis by human fetal lung in vitro. J Clin Endocrinol Metab 53:307

20. Mitzner M, Johnson JWC, Scott R, London WT, Palmer AE 1979 Effect of betamethasone on pressure-volume relationship of fetal rhesus monkey lung. J Appl Physiol Respir Environ Exercise Physiol 47:377

21. Nathanielsz PW, Silver M, Comline RS 1973 Plasma tri-iodothyronine concentration in the foetal and newborn lamb. J Endocrinol 58:683

22. Nwosu VC, Anday EK, Bolognese RJ, Bongiovanni AM, Delivoria-Papadopoulos M 1980 Effect of in utero intravenous administration of thyroxine and other hormones on the lung fluid lecithin/sphingomyelin ratio in the fetal lamb. Am J Obstet Gynecol 138:459

23. Redding RA, Douglas WHJ, Stein M 1972 Thyroid hormone influence upon lung surfactant metabolism. Science 175:994

24. Redding RA, Pereira C 1974 Thyroid function in respiratory distress syndrome (RDS) of the newborn. Pediatrics 54:423

25. Rooney SA, Gross I, Gassenhaimer LN, Motoyama EK 1975 Stimulation of glycerolphosphate phosphatidyltransferase activity in fetal rabbit lung by cortisol administration. Biochim. Biophys Acta 398:433

26. Sack J, Fischer DA, Lam RW 1975 Thyroid hormone metabolism in amniotic and allantoic fluids of the sheep. Pediatr Res 9:837

27. Wu B, Kikkawa Y, Orzalesi MM, Motoyama EK, Kaibara M, Zigas CJ, Cook CD 1973 The effect of thyroxine on the maturation of fetal rabbit lungs. Biol Neonate 22:161 